\title{
Examination of rabbit liver by ultrasound
}

\author{
Victor Trotsenko*, Irina Trotsenko, Olga Bdyukhina, and Zhanbota Esmurzaeva \\ Omsk State Agrarian University, 1, Institutskaya square, Omsk, 644008, Russian Federation
}

\begin{abstract}
The article provides information on the study of the mechanical properties of isolated rabbit liver cells in terms of density, compressibility and ultra-sonic velocity. It was found that the values of the studied characteristics are mainly determined by the water content in the cells. The density, compressibility, and velocity of ultrasound in the cellular material are interconnected by a linear relationship.
\end{abstract}

\section{Introduction}

Ultrasound examinations of animal organs for diagnostic and research purposes are now becoming more and more accessible, as they contribute to improving the tactics of differential diagnosis of diseases of internal organs [15]. Ultrasound examination is a method of examining the body using ultrasonic waves, based on the piezoelectric effect. The tissues of the body resist the penetration of ultrasound in different ways, depending on the density of the tissues and the speed of movement of sound waves. For the study of organs, frequencies from 2 to $29 \mathrm{MHz}$ can be used, while the resolution of modern ultrasound devices can reach fractions of a millimeter.

Investigation of the corelation between the structure of the whole tissue and its acoustic properties is a primary concern in the study of the volume-elastic properties of isolated somatic cells. The volume-elastic properties in this case include the values of cells density and compressibility. They are necessary in calculation of various forces which influence upon the cells in the suspension in the ultrasonic field.

The study of the volume-elastic properties of cells in suspension is associated with certain difficulties, which are manifested in the fact that the density and compressibility of cells and the suspension medium at a concentration of $10^{6}-10^{7}$ cells per milliliter differs slightly from each other. To obtain these characteristics with satisfactory accuracy, it is necessary to make relative measurements of the speed of ultra-sound and cell suspension with a relative error of less than $0.01 \%$ [6].

Cell compressibility is calculated from the formula [6]. It was suggested that the suspension is an ideal mixture of non-interacting components. In this case, we suppose the formula with $\rho$ for density and $\beta$ for compressibility of the suspension:

$$
\begin{gathered}
\rho=\rho_{2} C+\rho_{1}(1-C) \\
\beta=\beta_{2} C+\beta_{1}(1-C)
\end{gathered}
$$

and $C$ is the volume concentration of the particles. The indices 1 and 2 are referred to the suspension medium and to the particles, respectively.

The value of the ultrasonic wave propagation velocity in the suspension is determined by the following formula:

$$
u=\sqrt{\rho \beta}=\sqrt{\left(\rho_{2} C+\rho_{1}(1-C)\right)\left(\beta_{2} C+\beta_{1}(1-C)\right)} .
$$

The aim of this work was to study the volume-elastic properties of isolated liver cells by measuring the ultrasound velocity and density, as well as the factors that determine the values of these characteristics.

\section{Materials and methods}

Young rabbits of the White Giant breed weighing 150$170 \mathrm{~g}$ were used in the work. For the preparation of isolated liver cells, the method of perfusion with $0.05 \%$ collagenase solution was used [6], [7]. The resulting cell suspension was washed three times by centrifugation of the finished culture medium No. 199 with the addition of $10 \%$ by volume of bovine blood serum [8-10].

The cell concentration was determined in a JSQA hemocytometer (relative error 5-10\%). The average diameter of the cells was determined by measuring their size in a microscope using an eyepiece micrometer. When measuring 150-200 cells, the relative error of the average measurement did not exceed $5 \%$. For artificially change of cell density, they were kept for 4 hours in solutions of different ionic strengths from 0.05 to $0.35 \mathrm{M}$ according to $\mathrm{NaC} 1$.

The integrity of cell membranes was determined by eliminating the dyes trypan blue $(0.05 \%)$ and eosin $(0.1 \%)$. The dry weight of the cells was determined by drying $5 \mathrm{ml}$ of the suspension in a glass cup at $110^{\circ} \mathrm{C}$ for 10 hours. Together with the suspension, equal volumes of filtrates were dried, and then the weight of the salt residue was subtracted from the weight of the dry residue of the suspension. The relative error in determining the dry weight of the cells did not exceed 3$4 \%$.

* Corresponding author: vv.trotsenko@omgau.org 
The ultrasound velocity in the liver cell suspension was measured using the DMV DL instrument. The device allows measuring the speed of ultrasound with a relative error of no more than $1 \%$. The density of the cell suspension was determined using a DMA-60 densitometer. The relative error of the density measurement did not exceed $1 \%$.

The cells contribution to the values of the ultrasound velocity and the suspension density at concentrations of 106-107 cells / $\mathrm{ml}$ is insignificant, and it is comparable to the spread of these values due to the error in the preparation of the suspension medium with the specified concentrations of components. In order to eliminate this error, the density and velocity of ultrasound in the suspension were measured in the suspension firstly. Then the cells were filtered out, and the filtrate was measured. The obtained data were used to calculate the increments of ultrasound density and velocity in the suspension per unit volume concentration of cells $\frac{\Delta u}{C}$ and $\frac{\Delta \rho}{C}$, where $\Delta u=u-u_{1}$ and $\Delta \rho=\rho-\rho_{1}$.

In each experiment, a filtrate was obtained from a part of the cell suspension using Millipore membrane filters with a pore diameter of 0.45 microns. The dry weight of the cells was determined by drying $5 \mathrm{ml}$ of the suspension in a glass cup at $110^{\circ} \mathrm{C}$ for 10 hours. Together with the suspension, equal volumes of filtrates were dried, and then the weight of the suspension salt residue was subtracted. The relative error in determining the dry weight of the cells did not exceed 3-4\%. All measurements were carried out at a constant temperature of $+25^{\circ} \mathrm{C}$.

\section{Results and discussions}

The results of a series of experiments on measuring the ultrasound velocity in liver cell suspensions obtained from different rabbits at different times are shown in Figure 1. The difference in ultrasound velocities in the cell suspension and in the corresponding filtrate
$\Delta u=u-u_{1}$ is plotted along the ordinate axis, and the cell concentration is plotted along the abscissa axis.

The value is $\Delta u$ (next - the increment of the ultrasound speed). The solid line shows the concentration dependence $\Delta u$ obtained by successive dilution of one of the cells studied by the suspension with its filtrate. Figure 1 shows that in the case of sequential dilution, when cells isolated from the liver of one animal are measured, the experimental points fall on one straight line (the correlation coefficient is 0.91), since the error in dilutions and the error in measuring the ultrasound velocity are small. Therefore, the variation of experimental points observed in Figure 1, obtained in insignificant measurements on cell suspensions of different rabbits, is due to differences in the properties of the cells, for example, their size, density, biochemical composition, and possibly functional state. To exclude the influence of cell size on the value of $\Delta u$, it is advisable to consider its dependence not on the number of cells, but on their weight concentration. This relationship is shown in Figure 2.

The resulting linear relationship means that, firstly, the value of ultrasound speed $u$ is determined mainly by the dry weight of the cellular substance in the suspension, and it does not depend much on the supramolecular organization of the cell. Secondly, the relative biochemical composition of cells isolated from different rabbits varies slightly. The second conclusion is made taking into account the known data on a significant difference in the specific contributions of the main biochemical components of biological tissues: proteins, lipids, low-molecular weight compounds, to the value of the ultrasound velocity in tissues [2].

The deviations of the experimental points in Figure 2 from the straight line, slightly exceeding the measurement errors, reflect the scale of possible influence of differences in the biochemical composition of cells. The cells were isolated from the liver of different rabbits on the value of $\Delta u$.

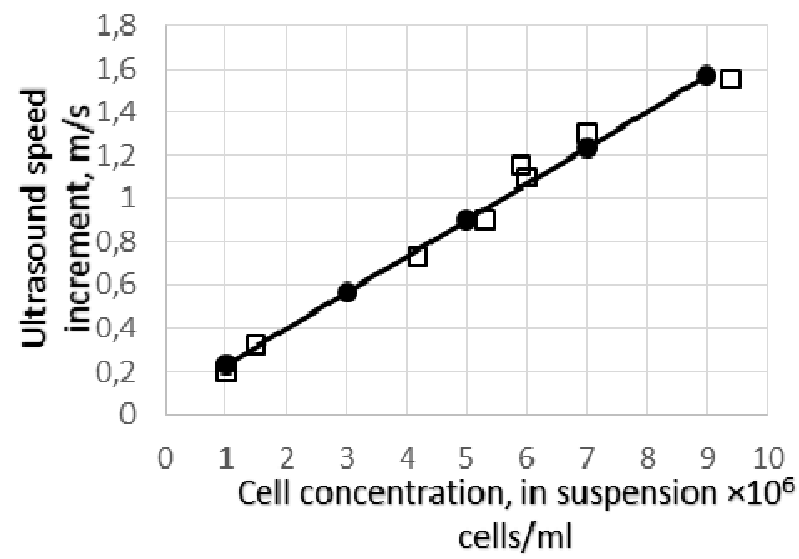

Fig. 1. The dependence of the value of the ultrasound velocity increment $\Delta u$ on the concentration of cells in the suspension. The squares indicate the results of measurements in cell suspensions obtained from different rabbits. The concentration dependence $\Delta u$, obtained by successive dilution of one of the studied suspensions with its filtrate, is shown by black circles connected by a solid line. 


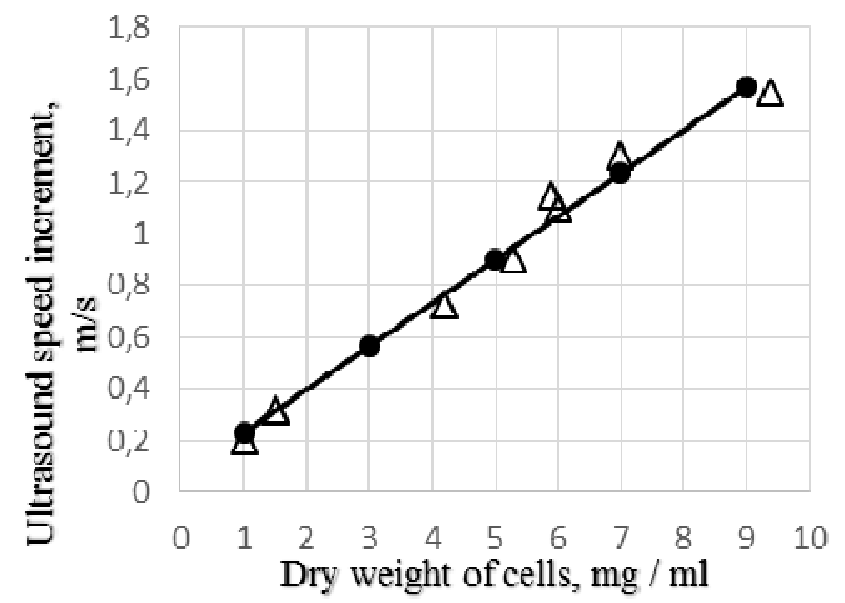

Fig. 2. Dependence of the increment of the ultrasound velocity of the dry weight of the cells in the unit volume of the suspension.

Among the molecular components of biological tissues and cells, the largest weight share $(70-80 \%)$ is water. Water content is known to be a determining factor in the values of the acoustic characteristics of tissues [5]. Therefore, the simplest way to experimentally change the mechanical properties of cells is a dosed change in the ionic strength of the suspension medium. For example, such change in the concentration of $\mathrm{NaC} 1$ will lead to the water content change in the cells under the influence of osmotic forces.

The change in the ionic strength of the medium affects both cells density of cells and their size: in hypertonic environments, the cells are compacted, and their size decreases. In hypotonic environments, the cells swell.

In order to determine the dependence of the mechanical characteristics of the cells on the ionic strength of the salt solution, cell density and ultrasound velocity were measured in suspensions with parallel control of changes in the average cell diameters. This dependence is shown in Figure 3 and Figure 4. Along the abscissa axis, the molar concentration of $\mathrm{NaCl}$ in the medium in which the cells were kept for 4 hours before the start of the measurements was deposited. It was found out that the cell diameter changed from 32 to 14 microns, and the density increased from 1.02 to 1.10 $\mathrm{g} / \mathrm{cm}^{3}$ or more when the ionic strength of the solution changed. The cells were kept for 4 hours before the start of measurements from 0.05 to $0.35 \mathrm{M} \mathrm{NaCl}$ in the solution.

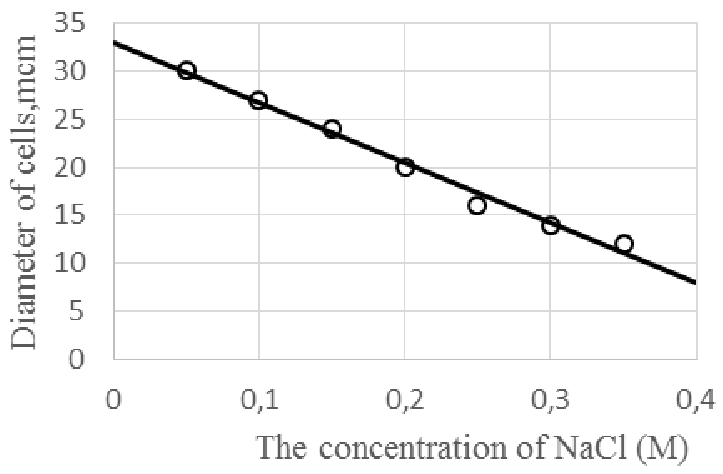

Fig. 3. Diameter of cells versus the concentration of $\mathrm{NaCl}$.

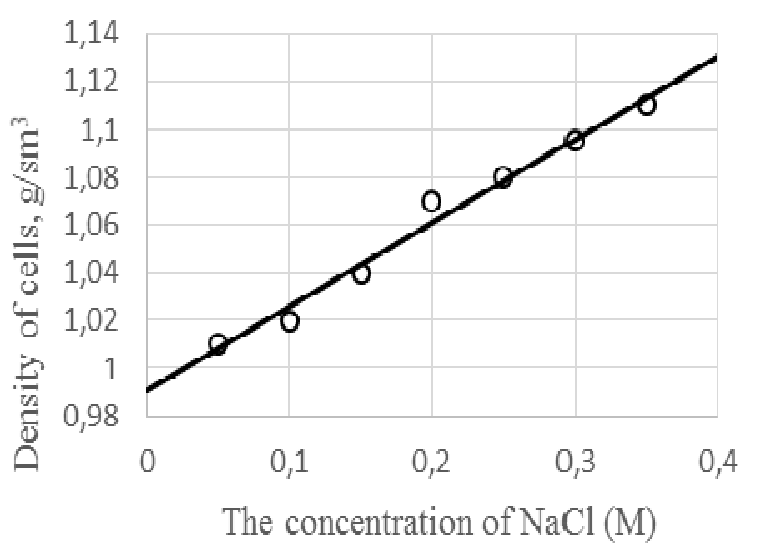

Fig. 4. Density of cells versus the concentration of $\mathrm{NaCl}$.

The obtained dependences are approximated by the equations:

$$
\begin{gathered}
D=-62.8 C+33 ; \\
\rho=0.35 C+0.99
\end{gathered}
$$

with the confidence coefficient of the approximation $\eta^{2} \geq 0.95$.

The ultrasound velocity in the cell material and their compressibility were calculated from the formulas (2) and (3). The results of the experiments show that ultrasound velocity in the cell material, density, and adiabatic compressibility normally vary within the following limits:

$u=1548 \pm 15 \mathrm{~m} / \mathrm{s}$;

$\beta=(40.5 \pm 0.95) \cdot 10^{-13} \mathrm{~Pa}^{-1}$ at $25^{\circ} \mathrm{C}$.

Figure 5 shows the relationship between the value of the ultrasound velocity in the cell material and the density of liver cells sustained in solutions of different ionic strength.

Figure 6 illustrates the dependence of the value of adiabatic compressibility on the density of liver cells sustained in solutions of different ionic strengths. 


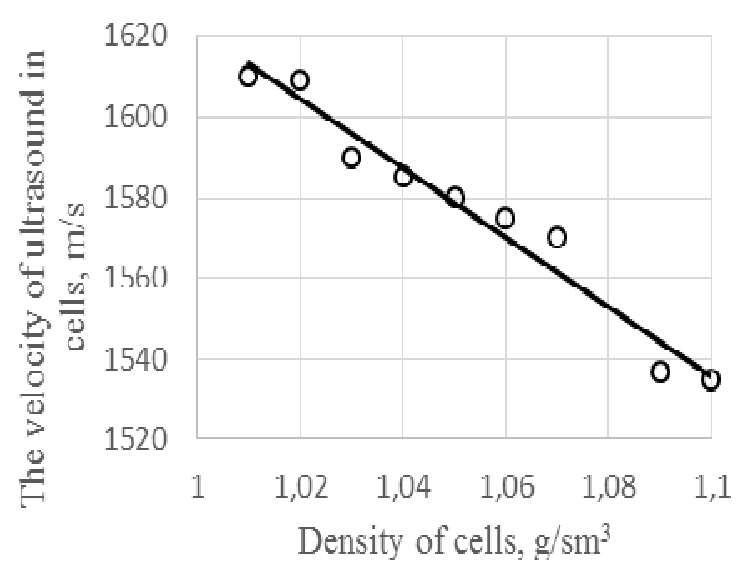

Fig. 5. Relationship between the value of the ultrasound velocity in the cell material and the density of liver cells sustained in solutions of different ionic strengths.

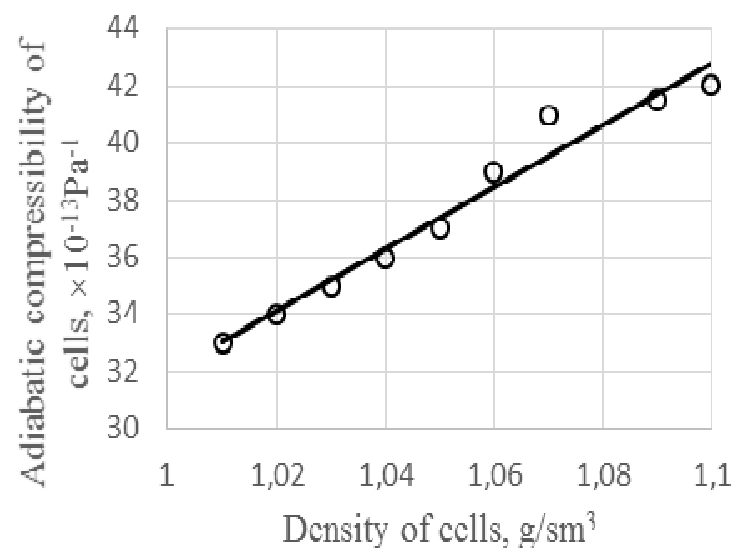

Fig. 6. The dependence of the value of adiabatic compressibility on the density of liver cells sustained in solutions of different ionic strengths.

These dependencies are approximated by the equations:

$$
\begin{array}{r}
u=-857.6 \rho+2478.6 ; \\
\quad \beta=108.2 \rho-76.3
\end{array}
$$

with the confidence coefficient of the approximation $\eta^{2} \geq 0.95$.

It was also found that a relative change in cell density, for example, by $10 \%$ leads to a relative change in the ultrasound velocity in the cell material by $5 \%$.

\section{Conclusion}

The density and adiabatic compressibility of isolated hepatic cells and the ultrasound velocity in the material of these cells at $23^{\circ} \mathrm{C}$ normally vary within the following limits:

$$
\begin{gathered}
u=1548 \pm 15 \mathrm{~m} / \mathrm{s} ; \rho=1.056 \pm 0.023 \mathrm{~g} / \mathrm{cm}^{3} ; \\
\beta=(40.5 \pm 0.95) \cdot 10^{-13} \mathrm{~Pa}^{-1} \text { at } 25^{\circ} \mathrm{C} .
\end{gathered}
$$

It is shown that the main parameter of cells that determines the values of the studied characteristics is the water content in the cells.
It was found that the density and compressibility of cells, as well as the speed of ultra-sound in the cell material, are related by a linear relationship.

\section{Acknowledgments}

The team of authors would like to express gratitude to the Center of Collective Use «Agrarian and Technological Research» and LLC «Certificate» for the opportunity to conduct research and obtain reliable data.

\section{References}

1. S.V. Chernigova, Y.V. Chernigov, Y.A. Vatnikov et al., Special aspects of systemic inflammation course in animals, Veterinary World, 12(7), 932937 (2019)

2. E. Nechaeva, O. Bdyukhina, T. Mitsulya, Changes in the State of Cell Membranes of an Animal Organism Against the background of the Protective Effect of Antioxidants Under Conditions of High Temperature, Advances in Social Science, Education and Humanities Research, 393, 135-140 (2020)

3. V. Veretennikova, T. Boyko, V. Vlasenko, V. Shitikov, The "Urticostim" Phytocomposition's Impact on the Hematological and Immunological Status of Experimental Animals (2019). DOI: 10.2991/assehr.k.200113.130

4. I.P. Ivanova, I.V. Trotsenko, V.V. Trotsenko, Automation of Processes in Dairy Cattle Production, Journal of Physics: Conference Series, 582, 012035 (2019). DOI.ORG/10.1088/1757$899 X / 582 / 1 / 011001$

5. I.V. Temereva, T.B. Smirnova, O.V. Chemisenko, Agrochemical assessment of cultivation efficacy for different potato varieties on meadow-chernozem soils of the Irtysh river area in Western Siberia, IOP Conference Series: Earth and Environmental Science, 624, 012098 (2021). doi: 10.1088/17551315/624/1/012098

6. S.E. Gorelov, L.A. Zverokov, A.P. Sarvazyan, E.M. Shvirst, Mechanical properties of liver cells, Biophysics, 102, 23-31 (1984)

7. N.V. Penkov, V.A. Yashin, N.E. Shvirst, E.E. Fesenko Jr., E.E. Fesenko, On peculiarities of temperature dependences of water spectra in the terahertz frequency domain, Biophysics, 59(2), 220222 (2014)

8. E.E. Fesenko, E.L. Gagarinsky, A.S. Averin, A.E. Gurin, N.V. Shishova, N.E. Shvirst, M.V. Goltyaev, N.V. Grudinin, A.L. Kovtun, The condition of the rat myocardium and isolated sheep heart after prolonged 24-hour hypothermic preservation in a pressurized carbon monoxideoxygen gas mixture, Biophysics, 65(4), 666-675 (2020) 
9. M.H. Li, B. Li, Propagation of Leaky Interface Waves at a Solid Boundary under Pulse Excitation, Acoustical Physics, 66(6), 604-612 (2020). DOI $10.1134 /$ S1063771020060123.

10. V. I. Korenbaum, A. D. Shiryaev, Features of Sound Conduction in
Human Lungs in the $80-1000 \mathrm{~Hz}$ and 10-19 KHz Frequency Ranges, Acoustical Physics, 66(5), 548-558 (2020).

DOI 